\title{
Evaluation of conventional standards of nickel electroplating process for surface finish layer of AISI 316L stainless steel using copper rod bars as cathode
}

\author{
Patrick Munyensanga ${ }^{1, *}$, Susilo A. Widyanto ${ }^{1}$, Moh N.A. Aziz ${ }^{1,2}$, and Paryanto ${ }^{1}$ \\ ${ }^{1}$ Department of Mechanical Engineering, Diponegoro University,Jl. Prof. Soedarto, SH Tembalang \\ Semarang, Indonesia. \\ ${ }^{2}$ Department of Mechanical Engineering, 17 Agustus 1945 University J1. Semolowaru no.45 \\ Surabaya, Indonesia.
}

\begin{abstract}
Nickel electroplating process at UD Barito Electroplating is a modern methodology installed in an open complex environment and at controlled temperature with trust consideration of specimen composition. The evaluation of process at UD Barito has been undertaken by considering Stainless steel AISI 316L as specimen through a conventional nickel electroplating process. This paper presents the proper scientifically tool to be used at UD Barito in order to meet the time required and the surface layer quality of the electroplated product. The use of ultrasonic to replace air compressor assembly does not cause any harm to the surface finish smoothness and the quality of plated specimen given that the process is conventional. Concerning the process of 10 min compared up to $15 \mathrm{~min}$ of the process at UD Barito; showed the facility of ultrasonic assisted the electroplating process. This process is also a useful method in maintenance activities for surface cleaning and for product surface-layer quality enhancement through the coating process. From the data analyzed, the specimen has a hydrogen embrittlement rate range between 20 to $65 \%$ of Rockwell scale HRC52.
\end{abstract}

\section{Introduction}

Nowadays, alloy electroplating is widely used in the production of novel materials that require peculiar physical or chemical properties. Thin layers of iron-nickel alloys are of practical interest since these materials are greatly used in various industrial applications. Currently, small and medium industries are developing their process design, material strength, surface finish layer, as well as mechanical and chemical properties of this metal alloy. Alloy electroplating is one of the technique to improve mechanical and chemical properties of materials and has been widely used in the synthesis of Novel materials [1].

\footnotetext{
*Corresponding author: patrickmunye@gmail.com
} 
The nature of the mechanics can increase their resistance to wear and increase the violence. The coated chemical nature can hold corrosion while physical nature attributes smooth surface side and appearance. The metal coating process can be applied by Physical Vapor Deposition (PVD), Chemical Vapor Deposition (CVD), spraying and also by electroplating process [2]. Approximately 150,000 tons of electroplated nickel annually distributed to the worldwide market. Therefore, this widespread of useful coated properties and its versatility to the materials; give nickel-electroplating features to be a modification of composition properties of the material. This modification is done through an electrolyte change in composition and the operating conditions. These properties of nickel are designed to meet the demand from the operators [3].

This paper emphasizes on the time required to coat the surface finish layer of Stainless steel 314L (Table 1) through Nickel electroplating process by comparing the method at UD Barito electroplating. Through coating process, the specimen exhibits corrosion resistance, aesthetic appeal, adhesion reduction and resistance to high temperature from $\mathrm{Cu}^{2+}$ electrons. Many Studies has been conducted to this material manufacturing process design with nickel electroplating with the use of Conventional Ultrasonic. This process raise temperature of electrolyte solution from $40{ }^{\circ} \mathrm{C}$ to $60{ }^{\circ} \mathrm{C},[1,4,5,6]$.

Table 1: Chemical composition of STM 316L with314and420. (Source: Scielo)

\begin{tabular}{|l|l|l|l|}
\hline AISI & $\mathbf{3 0 4}$ & $\mathbf{3 1 6 L}$ & $\mathbf{4 2 0}$ \\
\hline \hline \%C & 0.0667 & 0.0180 & 1.3450 \\
\hline \hline \%Cr & 18.1200 & 16.9280 & 13.1000 \\
\hline \hline \%Ni & 9.5800 & 9.5800 & 5.300 \\
\hline \hline \%Mn & 0.6020 & 0.6020 & 0.7860 \\
\hline \hline \%Si & 0.3644 & 0.3644 & 0.4049 \\
\hline \hline \%Mn & 0.2898 & 0.2898 & 0.1338 \\
\hline \hline \%P & 0.0015 & 0.0015 & 0.0014 \\
\hline
\end{tabular}

\section{Metal Coating Technology}

Metal coating technology is a well-known technique in metal/alloy industries to improve the quality characteristics of the material. This improvement is expected to be achieved through reparation technique in physical, mechanical and decoration features. By considering the loss of resistance to wear or failed its chemical, physical and mechanical properties, the corroded material may be maintained through electroplating depending on the nature of the material. This is rooted from the fact that mechanical characteristics can increase the resistance to wear and increase the ferocity. In addition, the chemical nature can lessen the corrosion of failed material, while physical nature presents an attribute to surface layer smooth and appearance. The coating methods were developed with the advantages of Physical Vapor Deposition (PVD).

This deposition produces a thin layer in nanometer's level of the thickness and in micrometer process in the empty air (vacuums). The PVD coaters' manufacturers are now facing the race with galvanic coatings from new condition. Although the conditions have a significant substrate of the same size to the coatings surface layer. However, the chemical 
and plasma of material must be cleaned and then coated at the highest possible deposition rate. These parameters provide mass production ability to the industry by using only large PVD batch systems or in-line coaters, [7].

\section{Step process of Nickel electroplating for STM AISI 316L coating}

The electroplating is a process of silting metal layer in the electrolyte solution that assisted by the flow of electricity. The type of solution and electricity channeled through the electrodes influences the quality of electroplating layer, [2].

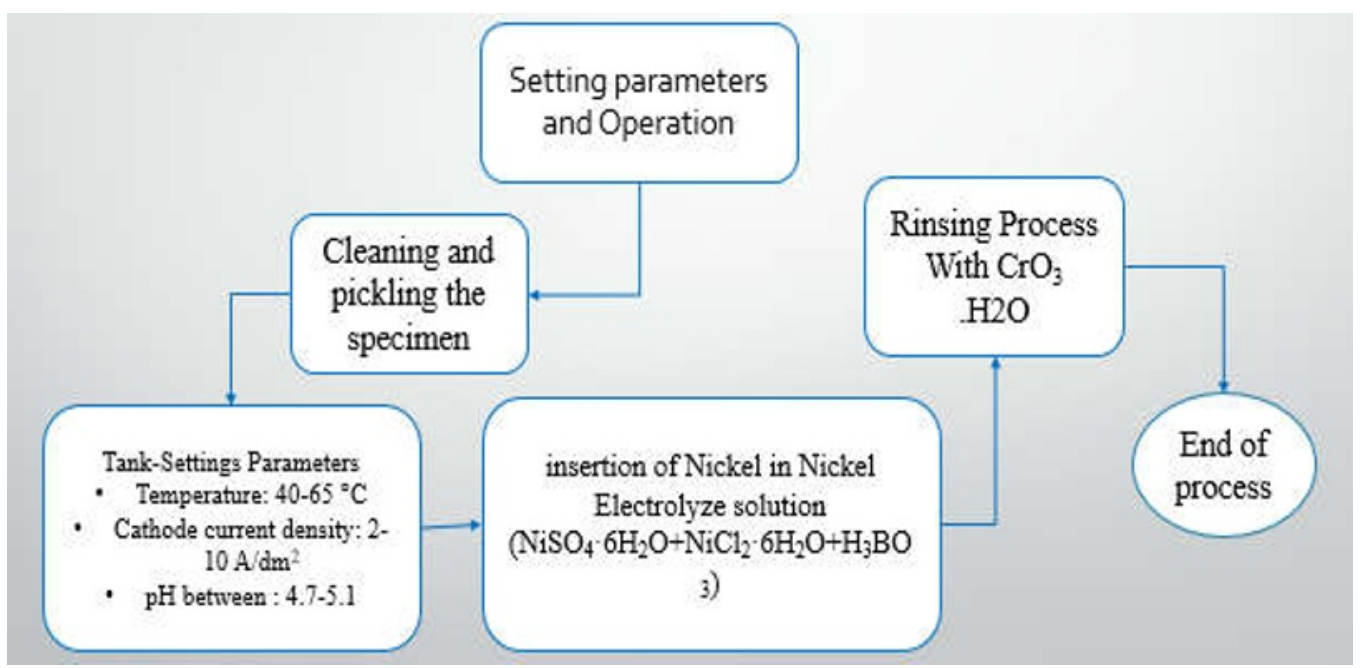

Fig. 1. Process stage of Nickel Electroplating at UD Barito electroplating

The process of electroplating (Figure 1) requires basic stage a) cleaning and pickling the surface to be electroplated $b$ ) activating coating process and maintain it after the specimen being cleaned and dried c) rinsing the STM AISI 316L after the electrolyte process. This stage includes the cleaning process with distilled water, soap and $32 \%$ of HCL for pickling.

The pickling is a combined process of cleaning the specimen STM AISI 316L. This sheets metal introduced into $\mathrm{HCl}$ dilute solution for 5 seconds; then blushed using distilled water $\left(\mathrm{H}_{2} \mathrm{O}\right)$ and soap. This process aims to eliminate corrosion, dust and other contaminants on the specimen. Yuliarto in his report from the view of Mika Makinen on nickel electroplating for STM AISI 316, show the effect of the laser engine additives on machine parts with different specific features when the parts have been electroplated [8]. These additives are present in manufacturing route for the condition of the surface layer. Mika gave the definition to the results on corrosion, age, life and friction of metal surface lay that occur from different stages [2]. For example of environmental exposition stage altered to the recommended exposition from the manufacturer.

In this process (Figure 2), metal sleeve material is placed on Anode. The nickel (Ni), copper $(\mathrm{Cu})$ and specimen STM 316L sheet metal to be coated have to be avail at this stage. The specimen object is placed on the Cathode and the initial electroless-plating layer of nickel offer to the surface layer a conductive tape on the specimen. 


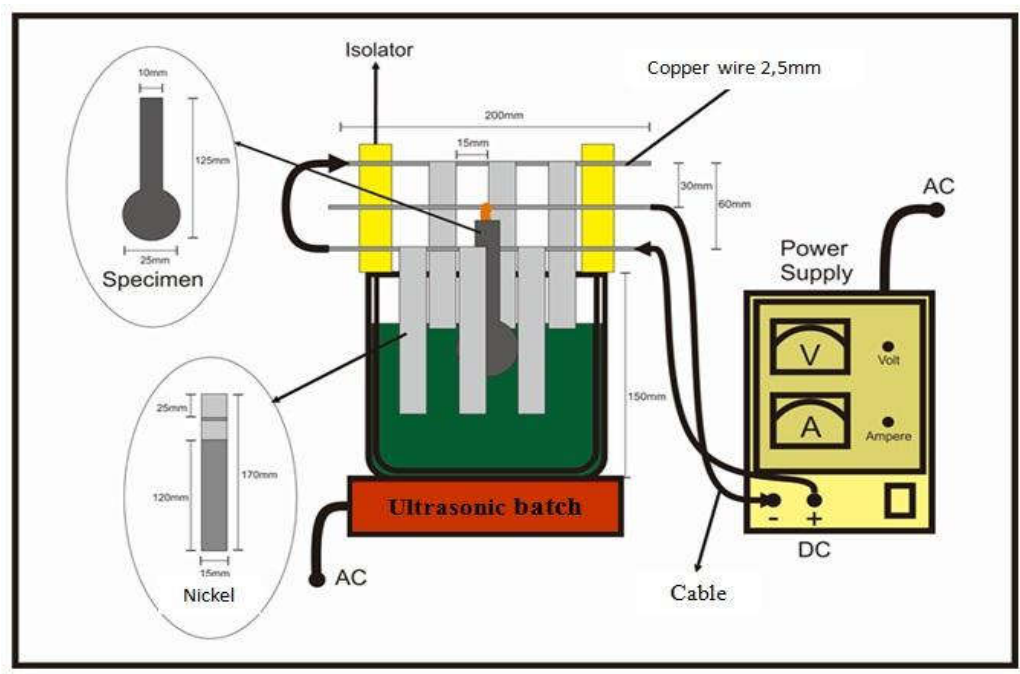

Fig. 2. Conventional nickel electroplating process diagram, (source:(2))

\section{Process description}

\subsection{Nickel electrolyte Preparation}

The pre-cleaned STM AISI 316L through pickling and brushed with soap water is now ready for nickel electroplating. The metal sleeve (copper rod bar) is placed on above of bath solution of Nickel chloride $\left(30 \mathrm{~g}\right.$ of $\left.\mathrm{NiCl}_{2} .6 \mathrm{H}_{2} 0\right)$, nickel sulfate $\left(300 \mathrm{~g}\right.$ of $\left.\mathrm{NiSO}_{4} \cdot 6 \mathrm{H}_{2} 0\right)$, boric acid $\left(30 \mathrm{~g}\right.$ of $\left.\mathrm{H}_{3} \mathrm{~B} 0_{3}\right)$, brighteners $\mathrm{I}(15 \mathrm{ml})$ and brighteners $\mathrm{II}(1 \mathrm{ml})$. Before dilution process, the bath composition dissolved in $1 \mathrm{~L}$ of distilled water preheated by hot plate stirrer at $40^{\circ} \mathrm{C}$. Dilution process conducts simultaneously with the stirring process at 48 -rpm speed rotation in 15 minutes. After the electrolyte, the solution is totally mixed and no sediment, the $\mathrm{pH}$ of electrolyte should be between 2 and 4.5.

The mounted stage respect the conventional process (Figure 2) as long the assembly tools chosen become intact in one unit system. This makes the electroplating system does not have the impurities or much external effect to the process. The equipment used for this process and stage facilitate easy of movement for Nickel ions $\mathrm{Ni}^{2+}$ and Copper ions, $\mathrm{Cu}^{2+}$ in $1 \mathrm{~L}$ of the electrolyte solution.

\subsection{Bath composition}

The material in nickel electroplating process identified as bath composition or nickel solution. This solution composed by the chemical material of nickel sulfate (NiS04.6H20), Nickel chloride $\left(\mathrm{NiCl}_{2} .6 \mathrm{H}_{2} 0\right)$ and Boric acid $\left(\mathrm{H}_{3} \mathrm{~B} \mathrm{O}_{3}\right)$. Since the process is regulated, the $300 \mathrm{~g} / \mathrm{L}$ of blue Nickel Sulfate solution $\left(\mathrm{NiSO}_{4} \cdot 6 \mathrm{H}_{2} \mathrm{O}\right)$ and is intuitively provide Nickel ions during the coating process. Bath solution is also composed of $30 \mathrm{~g} / \mathrm{L}$ of green Nickel Chloride $\left(\mathrm{NiCl}_{2}, 6 \mathrm{H}_{2} \mathrm{O}\right)$ diluted. The nickel chloride improves the conductivity of nickel ions with the flow of electricity from the anode to the cathode in solution.

In the electroplating process, the $\mathrm{PH}$ of the solution has to be maintained at a range between 2 to 4 . This range is retained by $530 \mathrm{~g} / \mathrm{L}$ of white Boric Acid $\left(\mathrm{H}_{3} \mathrm{BO}_{3}\right)$ and $15 \mathrm{ml}$ of benzene sulphonic acid. This sulphonic acid has an additional role to carry brighteners I after dilution. This brightener improves the structure of solution and results on extracted layers. For levelling agents after dilution, a $1 \mathrm{ml}$ of allyl sulfonic acid is used and then it fills the defect or the scratches of the substrate (specimen). 


\subsection{Electrolyte solution of Nickel electroplating process}

The main physical supportive equipment in the solution is adjustable and metering devices. A digital Scales Balance to measure the mass weight of the element in nickel electrolyte solution; Hot Plate Stirrer, for stirring process in 10 minutes with a rotation speed of $48 \mathrm{rpm}$ and temperature solution at $45^{\circ} \mathrm{C}$. For distillation, the Three Beaker glass used for measuring brighteners I\&II. Beaker serves for heating nickel electrolyte solution during the process. Beaker with $500 \mathrm{ml}$ for distilled HCL and Beaker with $10 \mathrm{ml}$ volume for liquid Brighteners. This process was conducted at variations of temperature; a Thermometer is used to measure the rise of the degree of internal heat for both electrolyte solution and dilution solution.

Stainless steel AISI 316L as Specimen to be coated and Nickel plate for maintaining the conductivity of Nickel ions $\mathrm{Ni}^{2+}$ during the electroplating process, this plate is a sleeve nickel metal. Copper rod bar with $2.5 \mathrm{~mm}$ diameter for hanger and $1.5 \mathrm{~mm}$ for the hinge of nickel plate of $1 \mathrm{~mm}$ thickness. This rod bar used as connectors of power to the Cathode terminal.

Since Nickel electroplating requires a flow of electricity, a DC power supply with 30 $\mathrm{V} / 5 \mathrm{~A}$ capacity manufactured by Jinwen inventor is used with function purpose of transform capacity of $\mathrm{AC}$ voltage to the required level. In addition, it serves as a rectifier of $\mathrm{AC}$ current signal to DC and as a filter that ripple of AC current signal. For protecting the process to the electric circuit breakage, the Isolator or inhibitor is placed in the electric assembly. The isolator is placed between positive pole and negative pole and serve as a separator between Anode and cathode to stay intact during the electroplating process. The Red and Black connecting wires to conduct electricity and electrolyte ions $\left(\mathrm{Ni}^{2+}\right.$ and $\left.\mathrm{Cu}^{2+}\right)$. These two wires are binding on the two poles of the system.

This experiment design uses Ultrasonic as a heating device (heater) of electrolyte solution during the process. This facilitates fluid agitation and produces a high strength movement for sleeve ions to adhere to the substrate (specimen). It also reduces the high iron percentage in Nickel alloying process for high corrosive resistance. The experiment design replaces manual air compressor assembly and this Ultrasonic for smoothing and clearing scientifically electroplating at UD Barito electroplating factory.

\subsection{Conventional Electroplating Process}

The Specimen rinsed and pickled before, it is immersed into the electrolyte solution as cathode acceptor and the nickel plate is deposed into electrolyte solution attached to anode side to be dissolved and form nickel ions $\left(\mathrm{N}^{2+}\right)$. These ions travel through the solution and cause the formation of Copper ions $\mathrm{Cu}^{2+}$ on the cathode of two negative bar (Figure 3 ). The STM AISI $316 \mathrm{~L}$ sheets metal which has been cleaned by water and soap for free of dirt and defects is immersed in the solution and hanged on copper rod bar of $2.5 \mathrm{~mm}$. Each of three sheets of the specimen is on one cathode rod bar; depending on the schematic of conventional nickel electroplating process diagram (Figure 2).

This process of Nickel electroplating with aid of Ultrasonic bath (Figure 3) raise the temperature from $45^{\circ} \mathrm{C}$ to $60^{\circ} \mathrm{C}$. A thermometer is used to precise the measurement. The ultrasonic bath is connected on inventor DC power supply with a capacity of $30 \mathrm{~V} / 5 \mathrm{~A}$ plugged on PLN electricity. All required parameters have to be steady; denote the mains setup and the time for coating. The process is turned on and the control, focus on ampere meter, located on the power supply. The Chronometer is controlled also for time regulation. During the experiment, the needs for electricity has to be controlled in accordance with the requirement of the expected result. 


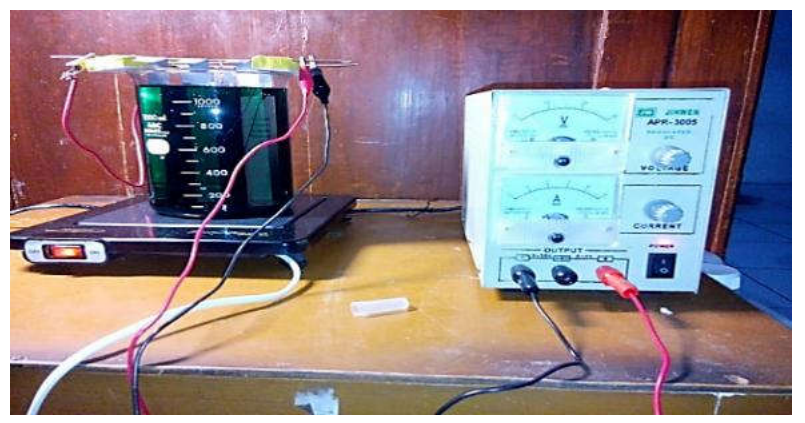

Fig. 3. Process layout of Nickel Electroplating with Ultrasonic

\section{Coated Specimen Parameters Analysis}

The coating process of the specimen surface finish layer is managed in $5 \mathrm{~min}$. This process has been conducted at $45^{\circ} \mathrm{C}$, the initial constant temperature of the electrolyte solution. The electric current variations of $0.3 \mathrm{~A}, 1 \mathrm{~A}, 1.5 \mathrm{~A}$ in this settled time with a $\mathrm{PH}$ level of 3.5. This phase of the test is done while the equipment coated is at free of impurities variable. This has been settled in order to meet the purpose of recovering the surface smoothness.

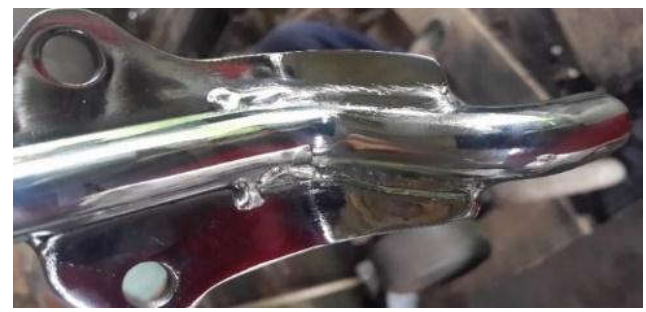

Fig. 4. STM AISI 316L specimen electroplated at UD Barito electroplating

The process used in this experiment was similar with the process implemented at UD Barito Electroplating, but the use of ultrasonic to replace Air compressor enhance agitation of electrons movement and reducing the high iron percentage in Nickel Alloy. Pickling process of the specimen is done before and after electroplating (Figure 4 by a rotating Sandpaper on an electric motor to remove all contaminants.

The Time consumed for coating was $10 \mathrm{~min}$, with $2 \mathrm{~A} / \mathrm{dm}^{2}$ plating conditions of the specimen and electric current used. A DC current rectifier with a maximum of $3000 \mathrm{~A}, 20 \mathrm{~V}$ has been used when the electricity from PLN is off. The rectifier transformed DC current of 12 Volt Battery to a current ranging between 200A-250A. For the smooth surface finish, DC rectifier has been settled at $10 \mathrm{~V}$ at the maximum operation time of $10 \mathrm{~min}$. Then the Nickel plate immersed was positioned at 6 inches from one to another. During the process at UD Barito, Air is pumped into the electrolyte tank by a small compressor. After $10 \mathrm{~min}$, the specimen is rinsed by an electrolyte solution of Chromium Trioxide Anhydrous $\left(\mathrm{CrO}_{3}\right)$.

This experiment has a hydrogen embrittlement rate (Table 2) range between 20 to $65 \%$ of Hardness Rockwell Scale 52 (HRC52). This ranging rate is depending on the plating parameters considered during the process. Misumi-techcentral, present the possibilities occurrence of the hydrogen embrittlement exist to the substrate of the electroplating process. Since this specimen used as a cathode for the electrolysis (9). The cause of this embrittlement was thought to be from agent reduction in the electroless plating solution. This effect the loss in flexibility and elasticity characteristics properties specimen. 
Table 2: Hydrogen Embrittlement - Plating Embrittlement (source:(9)

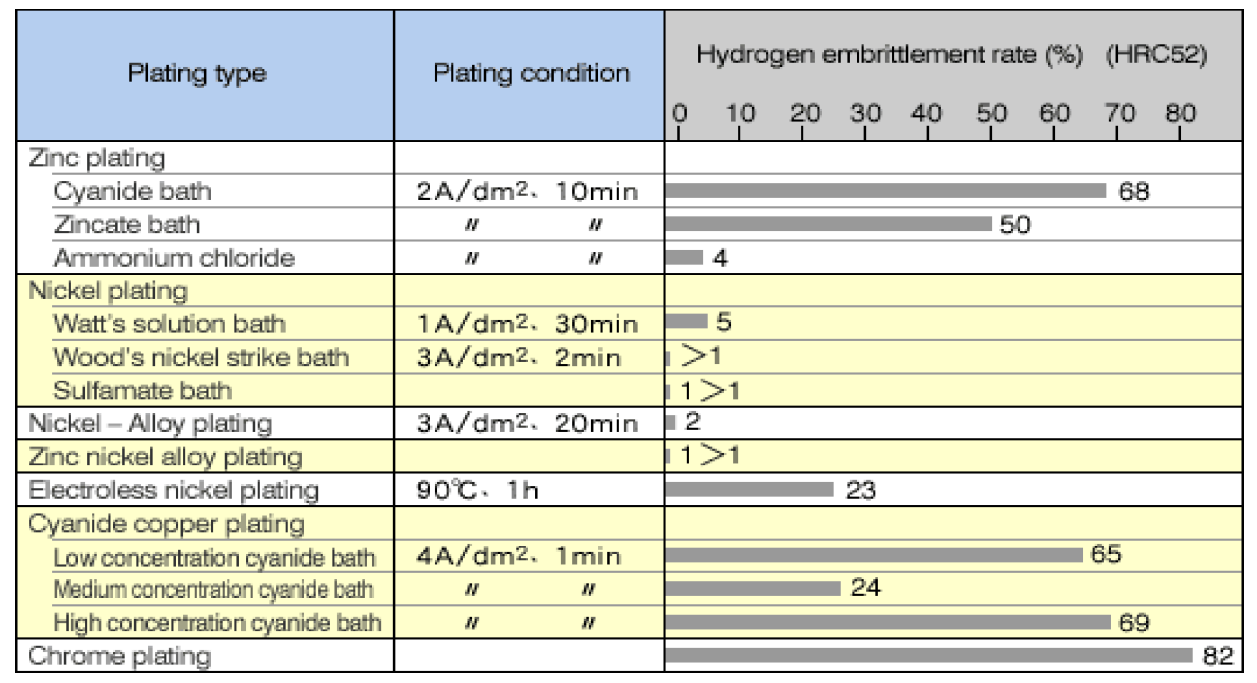

\section{Conclusion}

This experiment considers the chemical composition of the specimen and other variables of material. These parameters have been matched with the method used at Barito with Large batch systems, for continuous nickel electroplating process. The materials electroplated have various types of high rate deposition of impurities and corrosion on the surface layer. Pulse electroplating with $\mathrm{Ni}-\mathrm{W}-\mathrm{P}$ alloy coating has same parameters with this experiment of conventional nickel electroplating. The material pulsed has superior corrosion resistance $(276.8 \mathrm{k} \Omega)$ and compressed surface layer without any defect manifest [9]. This result gives the specimen coated through Nickel electroplating process has a resistance capability to corrosion at a range of $276.8 \mathrm{~K} \Omega$.

Nickel electroplating process is profitable and environmental for coating manufacturers. Since the specimen is in emergency demand. When material deteriorated or corroded, conventional electroplating method may solve time respondent of the failed device as long as the maintenance is based on servicing and surface recovering for the minimum time required in the electroplating process. The experiment conducted in $10 \mathrm{~min}$ proved for coated metal and with the hydrogen embrittlement range between 20 to $65 \%$ of HRC52. The ultrasonic can cause cavitation in the solution from the agitation and it enhances the surface finish hardness and roughness of the specimen.

\section{References}

1. Poroch-Seritan, Maria Cretescu, Igor Cojocaru, Corneliu Amariei, Sonia Suciu C. Experimental design for modelling and multi-response optimization of $\mathrm{Fe}-\mathrm{Ni}$ electroplating process. Chem Eng Res Des [Internet].. Available from: http://dx.doi.org/10.1016/j.cherd.2015.02.014, ;96:138-49,(2015)

2. Yuliarto Margen S. Elektroplating tesis sendie. (2018);

3. DiBari $G$ a. Nickel plating. Met Finish [Internet]. Available from: https://www.nickelinstitute.org/ /media/Files/TechnicalLiterature/NPH_141015.ashx. 97(1):27, (2014)

4. Oraon B, Majumdar G, Ghosh B. Materials \& Design Application of response surface method for predicting electroless nickel plating. Mater Des 27 1035-1045 [Internet]..Availablefrom:https://www.sciencedirect.com/science/article/pii/S02613069 05000440;27:1035-45, (2006) 
5. Chi-chang $\mathrm{Hu}$, Bai Allen. Optimization of hydrogen evolving activity on nickelphosphorus deposits using experimental strategies. Available from: https://link.springer.com/article/10.1023/A:1017525507665;5.65-72. (2001)

6. Chi-chang $\mathrm{Hu}$, Bai Allen. Composition control of electroplated nickel-phosphorus deposits. Surf Coatings Technol 1372001 181.187T [Internet]. Available from: https://www.sciencedirect.com/science/article/pii/S0257897200011178; 2-8; (2001)

7. Panjan P, Milos I. PVD coatings as an environmentally clean alternative to electroplating and electroless processes.;119:476-87. (1999)

8. Mäkinen Mika, Jauhiainen Eeva, Matilainen Ville-Pekka, Riihimäki Jaakko, Ritvanen J, Piili Heidi SA. Preliminary Comparison of Properties between Ni-electroplated Stainless Steel Parts Fabricated with Laser Additive Manufacturing and Conventional Machining. PhysProcedia[Internet]. Availablefrom:

http://dx.doi.org/10.1016/j.phpro.2015.11.048;78(August):337-46; (2015)

9. Misumi-techcentral. Surface Finishing [Internet]. misumi-techcentral. [cited 2018 Apr 12]. Available from: http://www.misumi-techcentral.com/tt/en/surface/2009/08/;(2009)

10. ZHOU, Hai hui LIAO, Zuo wei FANG, Chen xu LI H xin, FENG, Bin XU, Song $\mathrm{CAO}$, Guo fei KUANG Y fei. Pulse electroplating of Ni-W-P coating and its anticorrosion performance. Trans Nonferrous Met Soc China (English Ed [Internet]. Available from: http://dx.doi.org/10.1016/S1003-6326(18)64641-2;28(1):1-8; (2018) 